\title{
Bone tissue and mineral metabolism in hereditary endocrine tumors: clinical manifestations and genetic bases
}

\author{
Davide Maraghelli, Francesca Giusti, Francesca Marini and Maria Luisa Brandi*
}

\begin{abstract}
Inherited endocrine tumors are neoplasms of endocrine cells, transmitted via autosomal dominant germinal mutations. They present in two different forms: non-syndromic (patient has a single affected endocrine organ during his/her lifetime) or syndromic forms (multiple tumors in endocrine and non-endocrine organs during his/her lifetime). In addition to their common tumoral manifestations, many of these diseases present clinical affection of bone tissues and/or mineral metabolism, both as secondary complications of primary tumors and as primary defects due to genetic mutation. To date, few studies have documented these bone complications, and there are no systematic reviews in this area.

We present a revision of medical literature about skeletal and mineral metabolism affections in inherited endocrine tumor syndromes, and studies, in cells and animal models, investigating the direct role of some genes, whose mutations are responsible for the development of endocrine tumors, in the regulation of bone and mineral metabolism.
\end{abstract}

Keywords: Hereditary syndromic endocrine tumors, Bone clinical affections, Genetic bases

\section{Background}

In addition to their common manifestations, almost all inherited endocrine tumor syndromes present features of bone and mineral metabolism, either as secondary complications of primary tumors or as a primary consequence of gene mutation. There are few descriptions of these bone phenotypes in literature, and a review is still missing. This paper reviewed skeletal and mineral metabolism complications in hereditary endocrine tumor syndromes, focusing also on a description of the in vitro and in animal model studies investigating the direct role of genes, responsible for syndromes, in bone modeling and remodeling and/or in mineral metabolism homeostasis.

\footnotetext{
* Correspondence: marialuisa.brandi@unifi.it

Department of Experimental and Clinical Biomedical Sciences, University of Florence, Largo Palagi, 1, 50139 Florence, Firenze, Italy
}

\section{Discussion}

\section{Hereditary endocrine tumors}

Endocrine tumors originate from specialized hormonesecreting cells. Most of these neoplasms specialize in synthesizing and secreting hormones (functioning tumors; FTs) and only a small portion lose the hormone-secretive ability (non-functioning tumors; NFTs). Few patients without a clinical family history develop endocrine tumors (sporadic forms), while most cases have mendelian heritability (inherited forms). Inherited forms can be nonsyndromic (only a single affected endocrine organ during lifetime) or syndromic (multiple tumors in endocrine and non-endocrine organs during lifetime). All syndromes have an autosomal dominant inheritance.

Hereditary non-syndromic forms include familial primary hyperparathyroidism (FPHPT), familial medullary thyroid carcinoma (FMTC), familial isolated pituitary adenoma (FIPA), and familial acromegaly (FA). 
Hereditary syndromic forms include Multiple Endocrine Neoplasia type 1, type $2 \mathrm{~A}$ and $\mathrm{B}$ and type 4 (MEN1, MEN2A, MEN2B and MEN4), von Hippel Lindau (VHL), hereditary Paraganglioma/Pheochromocytoma syndromes (PGL/PCC), Hyperparathyroidism-Jaw Tumor syndrome (HPT-JT), Cowden syndrome (CS), Carney Complex (CNC), Tuberous Sclerosis (TSC), and Neurofibromatosis type 1 (NF1).

\section{Multiple Endocrine Neoplasia type 1}

MEN1 is characterized by: 1) adenomas of parathyroid/adenomas of parathyroid (affecting over $90 \%$ of patients by the age of 50 and causing primary hyperparathyroidism (PHPT), which can be associated with hypercalcemia); 2) adenomas of adenohypophysis (mainly prolactin-secreting adenoma or, more rarely, non-functioning macroadenomas); 3) neuroendocrine tumors of gastro-entero-pancreatic tract (GEPNETs) [1]; (Table 1).

MEN1 is caused by germinal heterozygote inactivating mutations of the MEN1 tumor suppressor gene, encoding a nuclear protein (menin) that exerts key functions in the regulation of important biological processes (cell cycle, DNA repair, apoptosis, gene transcription, and osteoblast differentiation) [2]; (Table 1).

Menin interacts with many different proteins and is involved in the regulation of numerous molecular pathways, opening the possibility to have a wide spectrum of potential targets for molecular therapy of the syndrome. To date, in vivo studies on pancreatic NETs have shown efficacy towards epigenetic modulators such as bromo- and

Table 1 Bone phenotypes in hereditary endocrine tumors, and possible molecular involvement of responsible genes in the regulation of bone and mineral metabolism

\begin{tabular}{|c|c|c|c|c|}
\hline Syndrome & $\begin{array}{l}\text { Main clinical manifestations of the } \\
\text { syndrome }\end{array}$ & Skeletal manifestations & $\begin{array}{l}\text { Responsible } \\
\text { gene(s) }\end{array}$ & $\begin{array}{l}\text { Role of genes in bone and/or mineral } \\
\text { metabolism }\end{array}$ \\
\hline MEN1 & $\begin{array}{l}\text { PHPT, hypophyseal adenomas, GEP- } \\
\text { NETs, carcinoids, adrenal-cortical tumors }\end{array}$ & Osteoporosis and/or osteopenia & $\begin{array}{l}\text { MEN1 } \\
(11 \mathrm{q} 13)\end{array}$ & $\begin{array}{l}\text { Regulation of osteogenesis, promotion } \\
\text { of osteoblastic differentiation }\end{array}$ \\
\hline MEN2 & MTC, PHEO, PHPT, CLA, HD & $\begin{array}{l}\text { Marfanoid habitus, pectus excavatum, } \\
\text { pes cavus, equino-varus foot, femoral } \\
\text { epiphysiolysis, kyphosis, scoliosis and } \\
\text { increased joint laxity (MEN2B) }\end{array}$ & $\begin{array}{l}\text { RET } \\
(10 \mathrm{q} 11.21)\end{array}$ & $\begin{array}{l}\text { Possible up-regulation of } \\
\text { chondromodulin-1, which promotes } \\
\text { cartilage deposition and inhibits bone } \\
\text { deposition }\end{array}$ \\
\hline MEN4 & $\begin{array}{l}\text { PHPT, hypophyseal adenomas, adrenal, } \\
\text { renal and reproductive organs tumors }\end{array}$ & Osteoporosis and/or osteopenia & $\begin{array}{l}\text { CDKN1B } \\
(12 \mathrm{p} 13.1-\mathrm{P} 12)\end{array}$ & $\begin{array}{l}\text { Regulation of longitudinal bone } \\
\text { growth and endochondral ossification }\end{array}$ \\
\hline VHL & $\begin{array}{l}\text { Retinal, cerebellar and medullary } \\
\text { hemangioblastomas, RCC, PHEO }\end{array}$ & No manifestation reported to date & VHL (3p25.3) & $\begin{array}{l}\text { Vascularization in endochondral and } \\
\text { membranous ossification }\end{array}$ \\
\hline $\begin{array}{l}\text { PGL/PCC } \\
\text { syndromes }\end{array}$ & Secreting PGL e PHEO, HNPGL & No manifestation reported to date & $\begin{array}{l}\operatorname{SDHx}(1 \mathrm{q} 21 ; \\
1 \mathrm{p} 36.1-\mathrm{p} 35 ; \\
11 \mathrm{q} 23 ; \\
11 \mathrm{q} 31.1)\end{array}$ & $\begin{array}{l}\text { No role of the SDHx genes on bone } \\
\text { metabolism reported to date }\end{array}$ \\
\hline HPT-JT & $\begin{array}{l}\text { PHPT, ossifying fibromas of the maxilla } \\
\text { and mandible, renal tumors and } \\
\text { adenomatous polyps of the uterus }\end{array}$ & $\begin{array}{l}\text { Osteoporosis and / or osteopenia, } \\
\text { ossifying fibromas of the maxilla and } \\
\text { mandible, osteitis fibrosa cystica }\end{array}$ & $\begin{array}{l}\text { HRPT2 / } \\
\text { CDC73 } \\
(1 \mathrm{q} 31.2)\end{array}$ & $\begin{array}{l}\text { Transcriptional repression of } \\
\text { osteoprogenitor cells necessary for } \\
\text { cellular survival and regulation of cell } \\
\text { differentiation and bone homeostasis }\end{array}$ \\
\hline CS & $\begin{array}{l}\text { Multiple hamartomas, susceptibility to } \\
\text { malignant tumors, skin and facial } \\
\text { changes, CNS abnormalities and } \\
\text { fibrocystic breast disease, thyroid } \\
\text { carcinoma }\end{array}$ & $\begin{array}{l}\text { Macrocephaly, bone cysts, thoracic } \\
\text { kyphosis, kyphoscoliosis, pectus } \\
\text { excavatum, large hands and feet, } \\
\text { syndactyly, maxillary and scapular } \\
\text { hypoplasia }\end{array}$ & $\begin{array}{l}\text { PTEN } \\
(10 q 23.3)\end{array}$ & $\begin{array}{l}\text { Regulation of osteoblastic apoptosis/ } \\
\text { survival, osteoblastic differentiation } \\
\text { regulation, indirect regulation of } \\
\text { chondrocyte adaptation to hypoxic } \\
\text { stress }\end{array}$ \\
\hline CNC & $\begin{array}{l}\text { Heart, endocrine, cutaneous and neural } \\
\text { myxomatous tumors, pigmented lesions } \\
\text { of skin and mucous membranes }\end{array}$ & Osteochondromyxomas & $\begin{array}{l}\text { PRKAR1A } \\
(17 \mathrm{q} 22-24) ; \\
\text { or possible } \\
\text { mutation in } \\
\text { 2p16 }\end{array}$ & $\begin{array}{l}\text { Osteoblastic differentiation and } \\
\text { promotion of osteogenesis }\end{array}$ \\
\hline TSC & $\begin{array}{l}\text { CNS, cardiac, renal, cutaneous, ocular } \\
\text { and pulmonary hamartomas; pancreatic } \\
\text { NETs, pituitary and parotid adenomas }\end{array}$ & $\begin{array}{l}\text { Metacarpal and metatarsal bone cysts, } \\
\text { sclerotic bone lesions }\end{array}$ & $\begin{array}{l}\text { TSC1 }(9 \mathrm{q} 34) \\
\text { and TSC2 } \\
(16 \mathrm{p} 13)\end{array}$ & $\begin{array}{l}\text { No studies are available to document } \\
\text { a direct role of TSC1 and TSC } 2 \text { in } \\
\text { bone metabolism }\end{array}$ \\
\hline NF1 & $\begin{array}{l}\text { Café-au-lait spots, Lisch nodules, } \\
\text { neurofibromas, neurofibrosarcomas, } \\
\text { gliomas, PHEO, myeloid leukemia and } \\
\text { GEP-NETs }\end{array}$ & $\begin{array}{l}\text { Kyphoscoliosis, macrocephaly, } \\
\text { sphenoid wing dysplasia, congenital } \\
\text { curvature, and tibial pseudoarthrosis }\end{array}$ & NF1 (17q11.2) & $\begin{array}{l}\text { Regulation of osteogenic proliferation } \\
\text { and differentiation, reduction of } \\
\text { expression of osteopontin } \\
\text { (calcification inhibitor) in pre- } \\
\text { osteoblastic MSC }\end{array}$ \\
\hline
\end{tabular}

Footnotes: PHPT: Primary HyperParaThyroidism; GEP-NETs: GastroEnteroPancreatic NeuroEndocrine Tumors; MTC: Medullary Thyroid Carcinoma; PHEO: PHEOchromocytoma; CLA: Cutaneous Lichen Amyloidosis; HD: Hirschsprung Disease; RCC: Renal Cell Carcinoma; PGL: ParaGangLioma: HNPGL: Head and Neck ParaGangLioma. 
extra terminal domain (BET) inhibitors, Wnt pathway targeting $\beta$-catenin antagonists, VEGF-signalling and mammalian target of rapamycin (mTOR) antagonists [3].

\section{Bone phenotype in MEN1}

Osteoporosis and osteopenia are frequent, early complications in MEN1 patients (Table 1]; reduction of bone mass is a common early clinical sign in MEN1 women by the age of 35 [4]. PHPT is the main cause of bone loss. The anticipated development of PHPT (20-30 years) can significantly interfere with the achievement of normal peak of bone mass, and untreated prolonged excessive secretion of parathyroid hormone (PTH) increases bone resorption, leading to early loss of cortical and trabecular bone. Early treatment of symptomatic PHPT, by successful subtotal parathyroid surgery, reduces skeletal damage, with significant improvement to BMD in the first 12 months [4].

Additional conditions may be considered risk factors for osteoporosis, such as hypogonadism, growth hormone deficiency, hypocortisolism due to pituitary disorders, as well as malabsorption caused by surgical resection of the proximal tract of the small intestine [5].

Despite a milder biochemical presentation, bone alterations in MEN1 PHPT are more severe than sporadic PHPT [6], indicating that bone phenotype in MEN1 is not just a secondary consequence of PHPT and suggesting a direct role of the MEN1 gene in bone physiology regulation.

Surgical removal of parathyroid adenomas, responsible for PHPT is the treatment of choice for restoring normal PTH secretion and serum level of calcium; parathyroidectomy demonstrated to normalize bone and mineral metabolism parameters. Medical therapy with cinacalcet demonstrated to be effective to control PTH oversecretion, and subsequent hypercalcemia, in patients who manifest PHPT recurrence or persistence despite one or more reoperations and in patients who are not suitable for parathyroidectomy. This calcimimetic molecule increases the sensitivity of the calcium-sensing receptor to extracellular calcium and induces a decrease in PTH secretion being able to normalize parathyroid functionality and, thus, bone turn-over.

\section{Role of the MEN1 gene in bone phenotypes}

Several studies, performed in MEN1 mice models and in cells, have confirmed direct important functions of wild type menin in regulation of osteogenesis and maintenance of bone mass. Heterozygous knock-out (KO) mice for the $\mathrm{Men} 1$ gene $\left(\mathrm{Men} \mathrm{1}^{+/-}\right)$showed a significant reduction in BMD, trabecular bone volume and cortical bone thickness, compared to control mice [7]. In $\mathrm{MenI}^{+/-}$mice, the number of osteoblasts and osteoclasts and rate of mineralization were reduced, while the number of osteocytes was increased [7]. Conversely, transgenic mice induced to overexpress menin showed an increase in bone mass, number of osteoblasts, and rate of mineralization [7].

Menin directly interacts with JunD, a transcription factor involved in negative control of cell proliferation and regulation of bone metabolism, repressing its activity [8]. JunD-deficient mice showed increased bone mass and trabecular number, associated with increased osteoblast activity [9]. The upregulation of JunD, caused by menin deficiency, could directly alter bone metabolism in MEN1 patients.

Menin has been shown to balance the commitment of mesenchymal stem cells (MSCs) to osteogenic or myogenic lineages. In response to BMP2, menin enhances the transcriptional activity of SMAD1/5factors, promoting osteoblastic differentiation of MSCs. Moreover, under the effect of TGF- $\beta 1$, menin reinforces repression of myogenic differentiation mediated by SMAD3/TGF $\beta 1$ [10]. When osteoblast activity is required, the expression of menin, in MSCs, is over-regulated. A reduction of wild type menin expression in these precursors can induce myogenesis [10].

Menin acts as direct positive regulator of miR-26a [11], a microRNA that negatively regulates the expression of SMAD1 protein during osteoblastic differentiation of MSCs [11].

Wild type menin directly increases the transcriptional activity of two steroid receptors exerting an important role in bone modeling and remodeling [the vitamin $\mathrm{D}$ receptor (VDR) and estrogen receptor $\alpha(\mathrm{ER} \alpha)]$. In parathyroid cells, vitamin D inhibits PTH transcription and cell proliferation; a reduction of VDR activity, following the loss of menin, could represent a facilitation for the growth of parathyroid cells and adenoma development [12].

\section{Multiple Endocrine Neoplasia type 2}

MEN 2 includes two clinical subtypes: 2A (MEN2A) and 2B (MEN2B) [13]. MEN2 tumors are medullary thyroid carcinoma (MTC), pheochromocytoma (PHEO) and, only in MEN2A, parathyroid adenoma/hyperplasia, associated with PHPT [14]; (Table 1].

MEN2 is caused by germinal heterozygote activating point mutations of the proto-oncogene RET (REarranged during Transfection; 10q11.21) (Table 1], encoding the homonym trans-membrane tyrosine kinase receptor (RET) responsible for positive regulation of cell growth. Different mutations are responsible for different clinical phenotypes. MEN2A patients have mutations at codons 634 (85\% of cases), 609, 611, 618 and 620 [15]. Over 90\% of MEN2B patients present the de novo M918T mutation [15-17]; mutation at codon 883 (A883F) affects about $5 \%$ of MEN2B patients. 
Since the early 2000s, targeted medical therapies have been introduced in MEN2 patients, especially designed for the treatment of MTC. They consists of antiangiogenic drugs and multi-targeted tyrosine-kinase inhibitors, not specifically directed against RET; for this reason the overall effectiveness is reduced and the incidence of drug resistance and side effects are increased [18]. Recently, quinazoline compounds, specific inhibitors of the RET thyrosine kinase pathway showed mild to significant anticancer efficacy in some tumor cell lines, including thyroid cancer, suggesting a possible future therapeutic potential in MEN2 [19].

\section{Bone phenotype in MEN2}

Skeletal affection in MEN2A is caused by PHPT, consisting in early reduction of BMD and increased risk of fracture [20, 21]. PTH normalization, following surgical removal of parathyroid adenoma, reverts the bone mass loss [19]. PHPT in MEN2A is usually milder than in MEN1 and BMD loss is less common and less severe [22].

MEN2B phenotype is characterized by typical musculoskeletal abnormalities, including marfanoid habitus with tall and slender body, long limbs, ogival palate, and long and thin face with prognathism. Bone abnormalities, such as pectus excavatum, hollow foot, equinovarus foot, femoral epiphysiolysis, kyphosis, scoliosis and increased joint laxity, are also present [23]; (Table 1).

For MEN2A-PHPT therapy with cinacalcet can be considered, with the same indication of MEN1. Not specific RET-targeted drugs for correction of bone affections in MEN2B patients are available or under evaluation, yet.

\section{Role of the RET gene in bone modelling}

Skeletal anomalies, manifesting in MEN2B form, can be ascribed to the specific $R E T$ mutations, affecting the intracellular domain of the protein and responsible for MEN2B phenotype. In fact, up-regulation of chondromodulin-1 (CHM1), a cartilaginous and bone growth regulator protein, normally expressed in proliferating and pre-hypertrophic chondrocytes of growth plates, was observed only in MTC samples of MEN2B patients. Increased transcription of CHM1 could be a direct result of signaling alterations secondary to the RET intracellular mutation, suggesting a possible relationship, not yet determined, between the two genes [24]. All MEN2B patients with skeletal anomalies had high expression of CHM1 [24]; (Table 1). In bone explants, the over-expression of CHM1 promotes cartilage deposition and inhibits bone formation. Chm1 mutant mice showed increased bone deposition [24]. Altered expression of CHM1 is suspected to alter the bone growth plate, leading to the skeletal abnormalities observed in MEN2B patients.

Activating mutations of the intracellular domain of RET could also be suspected to be responsible for the overexpression, in MEN2, of stanniocalcin-1 (STC1), a protein involved in the regulation of bone metabolism, by acting as an autocrine/paracrine regulator of calcium and phosphate homeostasis, with a role in early skeletal patterning and joint formation, [25]. The high expression of STC1 during embryogenesis could be associated with the marfanoid skeletal phenotype.

\section{Multiple Endocrine Neoplasia type 4}

MEN4 is characterized by multiple parathyroid tumors with associated PHPT (81\% of cases) and adenohypophysial tumors (42\%; ACTHoma with Cushing syndrome, GHoma, PRLoma, and non-functioning pituitary adenoma) (Table 1). Adrenal, renal and reproductive organ tumors, gastric and bronchial carcinoids and Zollinger-Ellison syndrome are also documented [26].

MEN4 is caused by inactivating heterozygous mutations of the CDKN1B tumor suppressor gene (12p13.1) (Table 1], encoding the $\mathrm{p} 27^{\mathrm{kip} 1}$ protein, a CDK2 cyclindependent kinase inhibitor, which acts as a negative regulator of cell cycle progression at G1-S checkpoint [27]. Mutations create an altered or truncated p2 $7^{\text {kip1 }}$ that is localized within the cytosol instead of the nucleus (contrary to the wild type counterpart), where it is not able to bind CDK2 [27].

Currently, only 19 cases of MEN4 have been described worldwide and, thus, no sufficient data are available about the efficacy of medical therapies for this syndrome. Therapeutic approaches follow the same guidelines of MEN1, and no specific research about possible gene therapies in patients with $C D K N 1 B$ mutations has been carried out yet. Application of p27 gene therapy was tested in human glioblastoma cells through CDKN1B-containing adenoviral vector transfection, showing promising anti-proliferation effects [28]. This finding can be a starting point for future research in p27 gene therapy also for MEN4 patients.

\section{Bone phenotype in MEN4}

Given the small number of MEN4 cases reported to date, no targeted studies on bone complications have been specifically conducted and data are not yet available in literature. However, since MEN4 presents a clinical phenotype overlapping that of MEN1, it is highly probable that PHPT-related hypercalcemia can alter bone metabolism and reduce BMD value the same way we find in MEN1 patients (Table 1).

\section{Role of the CDKN1B gene in bone and mineral metabolism}

Studies on Cdkn1b-KO mice showed increased growth in animals lacking $\mathrm{p} 27^{\mathrm{Kip} 1}$-mediated CDK2 inhibition, with a progressively growing effect with one or two silenced alleles. At cellular level, $p 27^{-1}$ mice showed increased proliferative activity of bone marrow cells and formation of numerous osteoblastic colonies. In the growth plate of developing organism, the expression of 
p2 $7^{\text {Kip } 1}$ is about two times lower than the surrounding bone cells of the epiphyseal and metaphyseal bone; this guarantees longitudinal bone growth (Table 1). p2 $7^{\text {Kip1 }}$ expression inhibits chondrocyte proliferation within growth plates and induces osteoblastic-like cell differentiation, via a BMP4-induced signaling pathway. Functional studies have shown that $\mathrm{p} 27^{\mathrm{Kip} 1}$ modulates the regulation of skeletal development and osteoblastic bone formation with a mechanism that implies its direct interaction with the PTH-related peptide (PTHrP) [29]. Homozygous mutant murine models for both $\mathrm{p} 27^{\text {Kip1 }}$ and Pthrp ( $227^{-1} /$ Pthrp KI) showed an increase in body weight, lifespan and growth of long bones, due to a higher proliferative state of growth plate, when compared to wild type and mutant models for Pthrp (Pthrp $K I)$ or $\mathrm{p} 27^{\mathrm{Kip} 1}\left(p 27^{\prime-}\right)$ [29]. BMD, cortical, epiphyseal and trabecular bone volume, number of osteoblasts and bone areas positive for type I collagen and osteocalcin, were all significantly increased in $p 27^{1-}$ mice and significantly reduced in Pthrp KI and $p 27^{-/} /$Pthrp KI mice, compared to wild-type mice. The same parameters significantly increased in $p 27^{1-} /$ Pthrp KI mice compared to Pthrp KI mice. Pthrp, Igf- 1 and Bmi-1 expression was increased in $p 27^{--}$mice and reduced in Pthrp KI and p27-/-/Pthrp KI mice with respect to wild type; expression of these three genes was increased in $p 27^{-1} / P t h r p$ KI mice compared to Pthrp KI mice [29]. The number of colonies-forming units-fibroblasts (CFU-f) and CFU-f positive for alkaline phosphatase (ALP) increased in $p 27^{-1}$ mice with respect to wild-type mice, and in p27//Pthrp KI mice compared to Pthrp KI mice. Conversely, there was a reduction of CFU-f in Pthrp KI and $p 27^{-/} /$Pthrp KI mice compared to wild-type. These data indicate that $\mathrm{p} 27^{\mathrm{kip} 1}$ may have an effect on recruitment and differentiation of bone marrow MSCs (BM-MSCs) [29]. $p 27^{/-}$mice also showed an increase of RANKL/ OPG ratio, presumably responsible for over-activation of osteoblast activity [29]. p27 ${ }^{\text {kip1 }}$ may be directly involved in the regulation of skeletal growth through its direct interaction with the C-terminal region and nuclear localization signals (NLSs) of PTHrP. This interaction leads to the inhibition of $\mathrm{p} 27^{\mathrm{kip} 1}$, enhancing the proliferation of chondrocytes and BM-MSCs and their differentiation into mature and active osteoblasts. The deletion of p27 $7^{\text {kip } 1}$ in Pthrp KI mice appears to partially compensate for bone growth defect and restore osteoblastic differentiation, increasing endochondral ossification and osteogenesis (Table 1), suggesting a possible future use of NLS and C-terminal regions of PTHrP to promote bone growth [29].

\section{Von Hippel-Lindau syndrome}

VHL predisposes development of various malignant and benign tumors, specifically, retinal, cerebellar and spinal hemangioblastomas, renal carcinomas (RCC), PHEO, and pancreatic tumors (Table 1). Hemangiomas of the adrenal glands, lungs and liver, and multiple cysts of the pancreas and kidneys, have been also described [30].

VHL is caused by inactivating mutations in the tumor suppressor gene $V H L$ (3p25.3) (Table 1), encoding the homologous protein ( $\mathrm{pVHL}$ ), which can be totally absent or inactive [31].

Normally, pVHL negatively regulates the hypoxia inducible factor $1 \alpha(\mathrm{HIF}-1 \alpha)$ responsible for cellular responses to hypoxia, including development of neoangiogenesis and induction of cell proliferation. Loss of wild type pVHL prevents degradation of HIF factors and induces responses to hypoxia, even when not physiologically required, inducing cell growth and formation of new vessels, thus favoring tumorigenesis [31].

Molecular therapy in VHL is precisely targeted towards genes regulated by HIF- $1 \alpha$, such as VEGF, PDGF- $\beta$ and TGF- $\alpha$, which have a fundamental role in tumorigenesis and angiogenesis. However, if anti-VEGF drugs, as bevacizumab, or multi-targeted receptor tyrosine kinase inhibitors, as sunitinib, have shown proven efficacy towards sporadic forms of cerebellar hemangioma, pancreatic NETs and RCC, a specific role of these agents in VHL patients, although used, is less clear [32]. Promising drugs in the future could be mTOR inhibitors: mTOR kinase in fact plays a critical role in the transcription and translation of HIF-2 $\alpha$; these inhibitors have shown positive activity in patients with sporadic pacreatic NETs but a possible benefit in patients with VHL mutations has not yet been sought [32].

\section{Bone phenotype in VHL and role of the VHL gene in bone tissue}

No clinical manifestations affecting bone and/or mineral metabolism were described in VHL patients (Table 1). No direct effects of VHL-related tumors on bone and mineral metabolism have been demonstrated. Indeed, only the complete loss of pVHL in cartilage cells can alter the correct bone growth and metabolism, as reported by studies in murine models with selective inactivation of the Vhlh gene only in the cartilaginous cells (Vhlh-null mice) [33]. While in VHL the somatic loss of heterozygosity of $V H L$ gene has been described only in retinal and CNS hemangioblastomas, RCC, PHEO, and pancreatic tumors. This fact can explain why VHL patients do not manifest bone alterations, despite the direct role of pVHL in bone modelling and endochondral ossification.

\section{Hereditary Paraganglioma-Pheochromocytoma syndromes}

PGL-PCCs are characterized by the presence of paragangliomas (PGLs) from the skull to the pelvis, and PHEOs (Table 1). Sympathetic PGLs and PHEOs secrete 
catecholamines, which are directly responsible for clinical symptoms, while parasympathetic PGLs are most often non-secretory, located in the head and neck, and symptoms depend on the compression of surrounding vascular-nervous structures [34].

PGL-PCCs are caused by germline mutations of genes encoding components of the enzymatic succinate dehydrogenase complex, or complex 2 , of the mitochondrial respiratory chain [35]; (Table 1). Different genes are responsible for specific PGL-PCC subtypes: SDHD (11q23) in PGL-PCC1, SDHC (1q21) in PGL-PCC3, SDHB (1p36.1-p35) in PGLPCC4, and SDHAF2 (SDH5) (11q31.1) in PGL-PCC2. Homozygous mutations of $S D H A$ gene (5p15) cause a clinical phenotype (Leigh syndrome) characterized by degenerative myeloencephalopathy.

The possible targets of molecular therapy in the PGLPCCs syndrome belong to the hypoxia-associated signal pathway. Indeed, mutations of $S D H x$ genes induce energy metabolism disorders and succinate accumulation, the last inhibits the activity of PHD2 and leads to increased activation of HIF- $\alpha$. SDHx-associated tumors are usually highly vascularized, thus, anti-angiogenic drugs can represent an effective treatment. A clinical study and case report demonstrated that oral sunitinib was effective in treating PCC/PGL SDHx-related [36]. Ethacrynic acid and idarubicin are other HIF inhibitors that may be studied in the future as specific target drugs in this hereditary syndrome [36].

\section{Bone affections in PGL-PCC}

No bone and/or mineral manifestations have been described in patients with PGL-PCC syndromes (Table 1). The only "intersection" between these syndromes and the skeleton are bone metastases in rare malignant forms of the disease, mainly localized in the rachis [37]. To date, no studies on animal models with mutations of $S D H x$ genes and bone diseases, nor specific studies that correlate the gene encoding components of the enzymatic succinate dehydrogenase complex or complex 2 of the mitochondrial respiratory chain with bone and/or mineral metabolism, have been published (Table 1).

\section{Hyperparathyroidism-jaw tumor syndrome}

HPT-JT syndrome is characterized by synchronous or metachronous onset of PHPT, ossifying jaw fibromas, renal tumors, adenomatous uterine polyps (Table 1), and an increased risk of renal hamartomas, adult Wilms tumors and parathyroid carcinoma [38]. PHPT occurs in about $95-100 \%$ of patients, due to single or multiple parathyroid adenoma, often recurrent after partial surgery [39]. PHPT can cause kidney stones and urinary tract infections [40].

HPT-JT is caused by inactivating germinal mutations of the HRPT2/CDC73 tumor suppressor gene (1q31.2)
[41]; (Table 1), encoding a nuclear protein called parafibromin, a component of the PAF1 complex, that is responsible for H3K4 histone trimethylation and H3K79 histone methylation. The interaction of parafibromin with this complex depends on its C-terminal domain, which is suppressed in about $80 \%$ of clinically relevant mutations. Mutations of $C D C 73$ also cause $C D C 73$-related isolated familial hyperparathyroidism and $C D C 73-$ related parathyroid carcinoma [40].

To date, there are no molecular targeted drugs acting on the CDC73/parafibromin pathway and effective for the treatment of HPT-JT.

\section{Bone phenotype in HPT-JT}

About $40 \%$ of HPT-JT patients develop ossifying jaw fibromas [40]; (Table 1), microscopically consisting of bone trabeculae with inhomogeneous fibrocellular stroma and mineralized matrix. These tumors may occur several decades before the development of hypercalcemia, suggesting that their development is not directly related to the increase of serum calcium [42]. Risk of post-surgical recurrence has been reported [43].

HPT-JT patients manifest PHPT with severe hypercalcemia if not diagnosed and treated early, resulting in possible development of severe bone resorption, osteopenia/ osteoporosis, bone pain, elevated risk of fragility fractures, hypercalciuria, and nephrolithiasis (Table 1). Severe and prolonged PHPT (mainly from parathyroid carcinoma) alters bone metabolism and may give rise to multiple brown tumors (osteitis fibrosa cystica) (Table 1). They normally regress after normalization of serum calcium and $\mathrm{PTH}$, following surgical removal of parathyroid tumor(s) [44].

\section{Role of the CDC73 gene in bone phenotype}

Direct functions of parafibromin in bone tissue were studied by using murine models with a selective conditional deletion of the $C d c 73$ gene in MSCs, mature osteoblasts and osteocytes. Homozygous deletion of $\mathrm{Cdc73}$ in MSCs resulted in embryos non-presenting mesenchymal development of the internal organs. The immunohistochemical staining of inactive and active caspase- 3 revealed a high rate of apoptosis of MSCs [45]. Conversely, selective homozygous elimination of $C d c 73$ in mature osteoblasts and osteocytes generated mice with normal life span, but increased cortical and trabecular bone [45]. This increment is associated with the presence of large cortical pores actively undergoing bone remodeling. The femoral cortical bone contained osteocytes with large amounts of cytosol and a high rate of apoptosis. Genes up-regulated in bone tissue in the absence of $C d c 73$ are components of the extracellular bone matrix (type 1 collagen, integrins, aggrecan, matrilin, ligand of chemokines 2 and 10), while down-regulated genes are related to transcription and mitotic processes (Sept10, Anapc13, Med16, MAPK, Rab1b, 
and Elk1) [45]. A hypothesis is that, in MSCs, parafibromin acts as a transcriptional repressor, necessary for cell survival and involved in regulation of cell differentiation and bone homeostasis [45]; (Table 1).

\section{Cowden syndrome}

CS is characterized by multiple hamartomas and increased risk of developing malignancies, skin and facial changes (trichilemmoms, papillomatous papules, and acral keratoses), CNS abnormalities, and fibrocystic breast disease [46]; (Table 1). The most frequent malignant tumors are ductal adenocarcinoma of the breast and papillary and follicular carcinoma of the thyroid. Polyposis of the gastrointestinal tract is frequent (70-85\%) [46].

PTEN (Phosphatase and TENsin homolog; 10q23.31), a tumor suppressor gene encoding a lipid phosphatase protein that negatively regulates the $\mathrm{PI} 3 \mathrm{~K} / \mathrm{AKT} / \mathrm{mTOR}$ signaling pathway, is the responsible gene [47-49]; (Table 1). Loss or reduction of PTEN activity results in increased phosphorylation of key cellular proteins, which can lead to uncontrolled cell cycle progression [50]. Over $80 \%$ of CS patients have a PTEN mutation [51]. Mutations in $S D H B, S D H D$ or $K L L N$ genes were recently identified in CS patients, with or without PTEN mutations [52].

No target therapies have been approved for CS patients but the upregulation of the PIK3/AKT/mTOR pathway suggests a role for therapies targeting this pathway [32]. Recently, a pilot study of sirolimus, a mTOR inhibitor, in 18 CS patients has shown that this drug is well tolerated in these subjects, and its administration is associated with improvement of symptoms, skin lesions, cerebellar function, and decreased mTOR signaling [53]. Selective PI3K beta inhibitors may have better activity and tolerability in patients with CS and other trials are investigating their role in patients with PTEN deficient advanced tumors [32].

\section{Bone phenotype in CS}

Several skeletal abnormalities has been reported in CS patients, including increased cranial size, bone cysts, thoracic kyphosis, kyphoscoliosis, pectus excavatum, large hands and feet, syndactyly, mandibular and maxillary hypoplasia, hypoplasia of shoulder blades, and osteosarcoma [46, 54, 55]; (Table 1). Data on the frequency of these abnormalities in CS patients are still lacking and a link with mutations of the PTEN gene has not been found [46].

\section{Role of the PTEN gene in bone phenotype}

Mice with osteoblastic precursors selectively lacking the Pten gene showed progressive and dramatic BMD increase over lifetime [56]; (Table 1). Pten-lacking osteoblastic precursors had greater differentiation potential than wild type counterparts, due to higher expression of beta catenin and subsequent activation of the Wnt signaling pathway. Pten-null osteoblasts expressed higher levels of osteogenic markers (ALP, osteocalcin, osteoprotegerin), associated with increased mineralization [57]; (Table 1).

A reduction of apoptosis has been reported in $\mathrm{Pten}^{-/-}$ chondrocytes of the growth plate, due to loss of Ptenderived hyper-activation of Akt [58]. Pten positively regulates the PI3K/Akt signaling pathway, which controls HIF- $1 \alpha$-mediated adaptation to hypoxic stress. Failure to express Pten induces stress of the endoplasmic reticulum and causes up-regulation of hypoxiainduced genes, including HIF-1 $\alpha$, [58]; (Tab.1). PTEN function in chondrocytes is essential for inhibiting dyschondroplasia; this could explain how the loss of PTEN protein has a direct pathogenic role in skeletal manifestations observed in CS patients [58].

\section{Carney complex}

$\mathrm{CNC}$ is characterized by heart mixomas, neural tumors and neoplasms of the endocrine system, and a variety of pigmented lesions of the skin and mucous membranes in typical sites (lips, conjunctiva, genital mucosa) [59]; (Tab.1). CNC has a remarkable clinical heterogeneity with generational leaps and prevalent maternal inheritance.

Linkage analysis studies on affected families have identified two genetic loci associated with $\mathrm{CNC}$ at 2p16 and 17q22-24 [60]; (Table 1). Based on these genetic alterations, CNC was subdivided into two subtypes: CNC1 (mutation on PRKAR1A gene at 17q22-24) and CNC2 (mutation at 2p16 locus). Approximately $60 \%$ of $\mathrm{CNC}$ patients bear an inactivating germline mutation of the PRKAR1A tumor suppressor gene, encoding the I-alpha regulatory subunit of cAMPdependent protein kinase (PKA) [61].

The cAMP analogue 8-Cl-adenosine has been shown in vitro to inhibit proliferation and promote apoptosis of cancer cells [62] and it could serve as a therapeutic agent in patients with CNC-related tumors.

\section{Bone phenotype in CNC}

A significant percentage of CNC patients develop bone tumors (osteochondromyxomas) (Table 1), characterized by layers of cells growing in macro- or micro-lobular patterns in a loose mixoid matrix, consisting of mesenchymal, cartilaginous, bone, and fibrous elements [63]. These tumors, prevalently located in the nasal region and diaphysis of tibia and radius, are usually painless and, therefore, detected during imaging evaluation for mass side effects [64, 65].

\section{Role of the PRKAR1A gene in bone phenotype}

Prkarla ${ }^{+/-}$mice showed large, hypocellular, bone lesions, composed of polygonal cells, with bone trabeculae 
surrounded by normal osteoblasts [63]. These mice developed bone tumors like human osteochondromyxomas, originating by MSCs differentiating into the osteoblastic line, although they appear arrested in a state of incomplete differentiation, as shown by the persistence of chondrocyte markers. Tumor cells show higher PKA activity and hyper-responsiveness to growth promoting effects of PKA activating agents (cAMP). Therefore, both increase in bone turnover and observed tumorigenesis are probably attributable to hyper-responsiveness to cAMP [66]. Analysis of gene expression of tumoral osteoblasts revealed reduced expression of osteoblastic differentiation markers and increased expression of local growth factors, including members of the Wnt signaling pathway [63].

The PKA signaling pathway is essential for bone mineralization in vitro and in vivo [66]. Loss of function and expression of the PRKAR1A gene leads to PKA level increase. Over-activation of PKA signaling causes fibrous dysplasia, an immature expansion of osteoblast precursors leading to structurally immature and hyper-proliferative bone. Expression of the I-alpha regulatory subunit of PKA increases during osteoblastic differentiation, suggesting its direct positive effect on the promotion of osteogenesis [66]. Conversely, the suppression of PRKAR1A gene expression could make cells refractory to the signals of osteogenic differentiation [66; Table 1). KO mice for Prkarla showed significant suppression of bone formation and reduced expression of osteoblastic markers, such as osteocalcin and osteopontin. The loss of Prkarla-encoded protein increases the activity of PKA, which inhibits the transcription of Runx 2 and its action on the target genes, and negatively regulates osteoblast differentiation [66]. The PKA signaling pathway, a key signal transduction pathway downstream of the PTH receptor (PTH1R) and PKA hyper-activation, resulting from the loss of PRKAR1A, could influence the PTH response [66].

PRKAR1A haploinsufficiency induces cyclooxygenase2 (COX2) activation and prostaglandin E2 (PGE2) overproduction, associated with abnormal proliferation of bone stromal cells of $\mathrm{CNC}$ osteochondromyxomas. Administration of celecoxib, a COX2 inhibitor, in mice with PKA defects decreased PGE2 level and reduced the proliferation of bone stromal cells, resulting in important reduction of osteochondromyxoma growth and better organization of the cortical bone adjacent to the mass [67]. This pivotal study suggests the possibility to use this drug for the treatment of bone affections in CNC.

\section{Tuberous sclerosis complex}

TSC is a complex genetic disorder characterized by the growth of numerous noncancerous (benign) nodular tumors (hamartoma) in the CNS (giant cell astrocytoma, cortical tubers, subependymal nodules), heart (rhabdomyomas), kidneys (angiomyolipomas and cysts), skin (hypo-pigmented spots), lungs (lymphangioleiomyomatosis), and retina. Associations with pancreatic NETs (especially insulinomas), pituitary and parotid adenomas have also been described [6870]:; (Table 1).

TSC is caused by loss-of-function mutations, either of the TSC1 gene (9q34), encoding hamartin, or the TSC2 gene (16p13), encoding tuberin [71]; (Table 1), with over half of the cases arising from non-inherited embryonal mutations. Both genes are tumor suppressors. Loss of one of the encoded proteins is sufficient for development of TSC, leading to a complete loss of hamartintuberin complex activity, with no inhibitory modulation on the mTOR signaling cascade and subsequent alteration of nutritional signal transduction and stimulation of cell growth $[68,72]$.

mTOR inhibitors (sirolimus, everolimus) are used in the clinical practice of TSC patients for the treatment of enlarging subependymal giant cell astrocytomas, renal angiomyolipomas $>4 \mathrm{~cm}$, or $>3 \mathrm{~cm}$ and growing rapidly, symptomatic cardiac rhabdomyomas and facial angiofibromas [73]. Recently, a study in a murine model of TSC with embryonic loss of Tsc1 in brain neurons, demonstrated the therapeutic efficacy of hamartin transfection by adenovirus vector, resulting in the normalization of neuron size and a decrease in markers of mTOR activation, with no side effects. Future studies are needed to evaluate the efficacy of this genetic therapy in humans [74].

\section{Bone phenotype in TSC}

Skeletal manifestations have been reported in TSC, mainly bone cysts in metacarpal and metatarsal bones, sclerotic bone lesions (SBL), and fibrous dysplasia [75]; (Table 1). SBLs, presumably originating from the neural crest, resemble dense, compact bone foci located within the bone marrow cavity, especially in the rachis and sacrum. Since SBLs normally do not produce symptoms, patients do not undergo biopsy, and no molecular studies have been performed on these lesions. Therefore, it is not known whether they follow a "second hit" pattern, like other TSC lesions [75].

The presence of SBLs in TSC patients and localization in the posterior structures of the vertebral bodies require differential diagnosis from osteoblastic metastases. The radiological characteristics of bone lesions detected by CT scan and MRI can help distinguish these bone pathologies [75].

\section{Role of TSC1 and TSC2 genes in bone phenotype}

Studies investigating a possible direct role of TSC1 and TSC2 genes in the regulation of bone metabolism are not available. However, the inactivation of the hamartintuberin complex causes hyper-activation of mTOR, resulting in uncontrolled cell proliferation and growth that could also occur in bone tissue. Only a small percentage 
(14\%) of patients without TSC1 or TSC2 mutations showed SBLs, while mutated patients develop SBLs in $84 \%$ of cases (of these, $47.2 \%$ have a pathogenic variant of TSC1 and $52.8 \%$ of TSC2) [75].

Early post-natal treatment with rapamycin, a mTOR inhibitor, in mice with a neural crest-specific Tsc1 deletion, prevented the growth of aberrant bone mass, whereas late treatment did not have this effect [76]. These data suggest that the increase of mTOR signal in the neural crest may expand the pool of osteoprogenitor cells at an early stage of the postnatal phase by promoting its proliferation; this is responsible for the increased number of osteoblasts and increase in bone mass in the later postnatal phase. At 1 month, the expanded pool of osteoprogenitor cells is already defined and its maintenance no longer requires an increased activity of mTOR. Therefore, late treatment with rapamycin is not effective in preventing excessive activity of osteogenic cells and consequent acquisition of localized excesses in bone mass. This suggests that it is necessary to identify a treatment window for successful management of bone manifestations in TSC.

\section{Neurofibromatosis type 1}

NF1 is characterized by a pathological triad: 1) multiple benign tumors of the nerves (neurofibromas); 2) pigmented skin lesions (café-au-lait spots and fibrous tumors); and 3) iris hamartomas (Lisch nodules) [67, 68]. Affected individuals have greater susceptibility to the development of benign and malignant tumors, such as neurofibromas, neurofibrosarcomas, gliomas, PHEO, myeloid leukemia, pancreatic and duodenal NETs (especially somatostatinomas) [77, 79]; (Table 1).

NF1 is caused by inactivating mutations of the NF1 tumor-suppressor gene (17q11.2) (Table 1), encoding neurofibromin 1, a negative regulator of the RAS transduction pathway, which regulates basic functions, such as proliferation, differentiation and apoptosis [77, 78].

The target therapy in NF1 is obviously focused on the RAS pathway, whose inhibition allows to treat multiple manifestations. Most of these drugs are not currently used in clinical practice yet but are subject to clinical trials: one of the most promising is Selumetinib, a MEK inhibitor (a downstream protein in RAS pathway), which has proven effectiveness in neurofibromas and low-grade gliomas. Other drugs that have shown encouraging results are anti angiogenic and mTOR inhibitors [80]. A recent study [81] has highlighted the possibility of restoring the correct RAS pathway via gene delivery, using a panel of adeno-associated virus vectors in peripheral nerve sheath tumor and human Schwann cells. The study showed a dramatically inhibition of the RAS pathway and tumor development, laying the foundations for a possible future gene therapy for NF1 [81].

\section{Bone phenotypes in NF1}

NF1 manifests various bone lesions (mainly involving long bones and vertebrae), such as kyphoscoliosis, macrocephaly, sphenoid wing dysplasia, and congenital pseudoarthritis of the tibia [82]; (Table 1). These skeletal manifestations affect over $50 \%$ of NF1 patients.

Less common skeletal manifestations include local overgrowth, abnormalities of the rib cage, rib fusion, genu varum/valgum, lytic bone lesions, osteosclerosis, absence of the patella, and syndactyly [73]. Bone lesions are mainly congenital and often associated with each other, strongly suggesting that NF1 has a direct effect on proper skeletal development and correct homeostasis of bone remodeling, and that its inactivating mutations are responsible for the development of NF1 bone complications.

NF1 patients show a higher incidence of osteopenia and osteoporosis compared to the general population [83]. Over $50 \%$ of NF1 patients show reduced BMD starting from childhood, not allowing the achievement of correct peak bone mass and predisposing them to a high risk of fragility fractures in adulthood. This reduced BMD can be the cause of long bones bending, mainly in the lower limbs (tibia and fibula).

Pseudarthritis is one of the most severe complications associated with NF1, still without effective therapy. Genes encoding epiregulin (EREG) and its receptor (epidermal growth factor receptor 1; EGFR1) are overexpressed in cells of the NF1 pseudarthrosis site. EGFR1 stimulation inhibits osteogenic differentiation. It has been hypothesized that increased EREG and EGFR1 expression in NF1-deficient skeletal progenitors may contribute to their reduced osteogenic differentiation potential. However, studies showed that drugs able to inhibit EGFR1 signaling are unlikely to have a significant benefit for the management of bone non-union in children with NF1 pseudarthrosis [84].

\section{Role of NF1 gene in bone phenotype}

Homozygous $N f 1-\mathrm{KO}$ mice $\left(N f 1^{-/-}\right)$died in utero, while heterozygous mice $\left(\mathrm{Nf1}^{+/-}\right)$showed no pathological involvement of bone tissue. Mice with a conditional specific inactivation of $N f 1$ in limb skeleton (Nf1Prx1 mice) showed two main signs: bowing of the tibia and diminished growth, the first due to decreased fitness of the cortical bone, the latter to lower proliferation rates and differentiation defect of chondrocytes [85]. MSC cultures showed increased proliferation and reduced osteogenic differentiation (lower expression of osteocalcin and osteonectin) and mineralization (increased expression of osteopontin). Neurofibromin negatively regulates RAS in osteoblasts 
[83]; in absence of neurofibromin, the activation of RAS is constitutively maintained, with consequent increased cell growth and reduced cell differentiation.

All these data suggest that neurofibromin is an important modulator of skeletal development and growth, and that somatic loss of the wild type NF1 allele in osteoprogenitor cells is necessary to develop NF1-associated bone phenotypes.

\section{Conclusions}

Until now, medical and scientific studies on hereditary endocrine syndromes focused on the diagnosis and treatment of tumor manifestations, while associated skeletal and mineral metabolism abnormalities were poorly investigated.

An epidemiological and clinical investigation of bone phenotypes, and their incorporation into the phenotypic description of syndromes, can improve medical knowledge and favor the design of appropriate prevention and management of these complications.

Future studies need to address the genotype-phenotype relationships between gene mutations and severity of bone affections in larger population analyses.

The clinical management of congenital endocrine tumor syndromes can help see the role of "cancer" genes in the regulation of bone development and metabolism in physiological and pathological conditions.

\begin{abstract}
Abbreviations
ALP: Alkaline phosphatase; BMD: Bone mineral density; BM-MSCs: Bone marrow mesenchymal stem cells; CFU-f: Colonies-forming units-fibroblasts; CLA: Cutaneous lichen amyloidosis; CNC: Carney complex; CS: Cowden syndrome; ERa: Estrogen receptor a; FA: Familial acromegaly; FHH: Familial hypocalciuric hypercalcemia; FIPA: Familial isolated pituitary adenoma; FMTC: Familial medullary thyroid carcinoma; FPHPT: Familial primary hyperparathyroidism; FTs: Functioning tumors; GEP-NETs: Neuroendocrine tumors of gastro-entero-pancreatic tract; HD: Hirschsprung disease; HNPGL: Head and neck paraganglioma; HPT-JT: Hyperparathyroidism-Jaw Tumor syndrome; KO mice: Knock-out mice; MEN1: Multiple Endocrine Neoplasia type 1; MEN2 (A and B): Multiple Endocrine Neoplasia type 2 (A and B); MEN4: Multiple Endocrine Neoplasia type 4; MSCs: Mesenchymal stem cells; MTC: Medullary thyroid carcinoma; NF1: Neurofibromatosis type 1; NFTs: Non-functioning tumors; NLSs: Nuclear localization signals; PGLs: Paragangliomas: PGL/PCC: Hereditary Paraganglioma/ Pheochromocytoma syndromes; PHEO: Pheochromocytoma; PHPT: Primary hyperparathyroidism; PTH: Parathyroid hormone; PTH1R: PTH receptor; PTHrP: PTH-related peptide; RCC: Renal cell carcinomas; SBL: Sclerotic bone lesions; TSC: Tuberous Sclerosis Complex; VDR: Vitamin D receptor; VHL: Von Hippel Lindau
\end{abstract}

\section{Acknowledgements}

Not applicable.

\section{Disclosure summary}

The authors declare that they have no conflicts of interest. No grants or fellowships supported this paper.

\section{Authors' contributions}

Davide Maraghelli: Drafted the manuscript; he systematically read the articles of literature selected by the co-authors, extrapolating the data useful for writing the manuscript.
Francesca Marini: gave contributions in drafting the manuscript; she critically revised the manuscript for its contents, thanks to her knowledge of the genetic basis of these diseases.

Francesca Giusti: gave contributions in drafting the manuscript; she critically revised the manuscript for its contents, thanks to her knowledge of the clinical basis of these diseases.

Maria Luisa Brandi: Drew this study. She critically revised the manuscript for its contents and gave her final approval of the version to be published.

\section{Funding}

The writing of the manuscript was not supported by any fund.

\section{Availability of data and materials}

Not applicable: Data sharing is not applicable to this article as no datasets were generated or analysed during the current study.

\section{Ethics approval and consent to participate}

Not applicable: this manuscript does not report studies involving human participants, human data or human tissue.

\section{Consent for publication}

Not applicable: this manuscript does not contain any individual person's data in any form.

\section{Competing interests}

All the authors declare that they have no competing interests, associated with this manuscript.

Received: 11 November 2019 Accepted: 7 April 2020

Published online: 23 April 2020

\section{References}

1. Thakker RV, Newey PJ, Walls GV, Bilezikian J, Dralle H, Ebeling PR, Melmed S Sakurai A, Tonelli F, Brandi ML. Clinical Practice Guidelines for Multiple Endocrine Neoplasia Type 1 (MEN1). The Journal of Clinical Endocrinology \& Metabolism, Volume 97, Issue 9, 1 September 2012, Pages 2990-3011.

2. Chandrasekharappa SC, Guru SC, Manickam P, Olufemi SE, Collins FS, Emmert-Buck MR, Debelenko LV, Zhuang Z, Lubensky IA, Liotta LA, Crabtree JS, Wang Y, Roe BA, Weisemann J, Boguski MS, Agarwal SK, Kester MB, Kim YS, Heppner C, Dong Q, Spiegel AM, Burns AL, Marx SJ. Positional cloning of the gene for multiple endocrine neoplasia-type 1. Science. 1997;276(5311):404-7.

3. Frost M, Lines KE, Thakker RV. Current and emerging therapies for PNETs in patients with or without MEN1. Nat Rev Endocrinol. 2018;14(4):216-27.

4. Burgess JR, David R, Greenaway TM, Parameswaran V, Shepherd JJ. Osteoporosis in multiple endocrine neoplasia type 1: severity, clinical significance, relationship to primary hyperparathyroidism, and response to parathyroidectomy. Arch Surg. 1999;134(10):1119-23.

5. Kann PH, Bartsch D, Langer P, Waldmann J, Hadji P, Pfützner A, Klüsener J. Peripheral bone mineral density in correlation to disease-related predisposing conditions in patients with multiple endocrine neoplasia type 1. J Endocrinol Investig. 2012;35(6):573-9.

6. Eller-Vainicher C, Chiodini I, Battista C, Viti R, Mascia ML, Massironi S, Peracchi M, D'Agruma L, Minisola S, Corbetta S, Cole DE, Spada A, Scillitani A. Sporadic and MEN1-related primary hyperparathyroidism: differences in clinical expression and severity. J Bone Miner Res. 2009;24(8):1404-10.

7. Kanazawa I, Canaff L, Rafeh JA, Angrula A, Li J, Riddle RC, Boraschi-Diaz I, Komarova SV, Clemens TL, Murshed M, Hendy GN. Osteoblast Menin Regulates Bone Mass in Vivo. J Biol Chem. 2015;290(7):3910-24.

8. Agarwal SK, Guru SC, Heppner C, Erdos MR, Collins RM, Park SY, Saggar S, Chandrasekharappa SC, Collins FS, Spiegel AM. Menin interacts with the AP1 transcription factor JunD and represses JunD-activated transcription. Cell. 1999;96:143-52.

9. Kawamata A, Izu Y, Yokoyama H, Amagasa T, Wagner EF, Nakashima K, Ezura Y, Hayata T, Noda M. JunD suppresses bone formation and contributes to low bone mass induced by estrogen depletion. J Cell Biochem. 2008;103(4): $1037-45$.

10. Aziz A, Miyake T, Engleka KA, Epstein JA, McDermott JC. Menin expression modulates mesenchymal cell commitment to the myogenic and osteogenic lineages. Dev Biol. 2009;332:116-30. 
11. Luzi E, Marini F, Tognarini I, Galli G, Falchetti A, Brandi ML. The regulatory network menin-microRNA 26a as a possible target for RNA-based therapy of bone diseases. Nucleic Acid Ther. 2012;22(2):103-8.

12. Dreijerink KMA, Varier RA, Nuland RV, Broekhuizen R, Valk GD, Van der Wa JE, Lips CJM, Kummer A, Timmer M. Regulation of vitamin D receptor function in MEN1-related parathyroid adenomas. Mol Cell Endocrinol. 2009; 313:1-8.

13. Lodish M. Multiple endocrine neoplasia type 2. Front Horm Res. 2013;41:16-29.

14. Marini F, Falchetti A, Del Monte F, Carbonell Sala S, Tognarini I, Luzi E, Brandi ML. Multiple endocrine neoplasia type 2. Orphanet J Rare Dis. 2006;1:45.

15. Raue F, Frank-Raue K. Update multiple endocrine neoplasia type 2. Familial Cancer. 2010;9:449-57.

16. Carlson KM, Dou S, Chi D, Scavarda N, Toshima K, Jackson CE, Wells SA Jr, Goodfellow PJ, Donis-Keller H. Single missense mutation in the tyrosine kinase catalytic domain of the RET protooncogene is associated with multiple endocrine neoplasia type 2B. Proc Natl Acad Sci U S A. 1994;91: 1579-83.

17. Redaelli S, Plaza-Menacho I, Mologni L. Novel targeted therapeutics for MEN2. Endocr Relat Cancer. 2018;25(2):T53-68.

18. Hofstra RM, Landsvater RM, Ceccherini I, Stulp RP, Stelwagen T, Luo Y, Pasini B, Hoppener JW, van Amstel HK, Romeo G, et al. A mutation in the RET proto-oncogene associated with multiple endocrine neoplasia type $2 B$ and sporadic medullary thyroid carcinoma. Nature. 1994;367:375-6.

19. Pathak P, Naumovich V, Grishina M, Shukla PK, Verma A, Potemkin V. Quinazoline based 1,3,5-triazine derivatives as cancer inhibitors by impeding the phosphorylated RET tyrosine kinase pathway: design, synthesis, docking, and QSAR study. Arch Pharm (Weinheim). 2019;352(9):e1900053.

20. Gujral TS, Singh VK, Jia Z, Mulligan LM. Molecular mechanisms of RET receptor mediated oncogenesis in multiple endocrine neoplasia $2 B$. Cancer Res. 2006:66:10741-9.

21. Giusti F, Tonelli F, Brandi ML. Primary hyperparathyroidism in multiple endocrine neoplasia type 1: when to perform surgery? Clinics (Sao Paulo). 2012;67(Suppl 1):141-4

22. Malone JP, Srivastava A, Khardori R. Hyperparathyroidism and multiple endocrine neoplasia. Otolaryngol Clin N Am. 2004;37(4):715-36 viii.

23. Lee NC, Norton JA. Multiple endocrine neoplasia type 2B-genetic basis and clinical expression. Surg Oncol. 2000;9:111-8.

24. Jain S, Watson MA, DeBenedetti MK, Hiraki Y, Moley JF, Milbrandt J. Expression profiles provide insights into early malignant potential and skeletal abnormalities in multiple endocrine Neoplasia type 2B syndrome Tumours. Cancer Res. 2004;64:3907-13.

25. Stasko SE, Wagner GF. Possible roles for stanniocalcin during early skeletal patterning and joint formation in the mouse. J Endocrinol. 2001;171(2):237-48.

26. Brandi ML (expert reviewer). MEN4, Orphanet encyclopedia, 2015, https:// www.orpha.net/consor/cgi-bin/OC_Exp.php?Lng=EN\&Expert=276152.

27. Pellegata NS. MENX and MEN4. Clinics (Sao Paulo). 2012;67(Suppl 1):13-8.

28. Park KH, Lee J, Yoo CG, Kim YW, Han SK, Shim YS, Kim SK, Wang KC, Cho BK, Lee CT. Application of p27 gene therapy for human malignant glioma potentiated by using mutant p27. J Neurosurg. 2004;101(3):505-10.

29. Zhu M, Zhang J, Dong Z, Zhang Y, Wang R, Karaplis A, Goltzman D, Miao D. The p27 pathway modulates the regulation of skeletal growth and Osteoblastic bone formation by parathyroid hormone-related peptide. J Bone Miner Res. 2015;30:1969-79.

30. Varshney N, Kebede AA, Owusu-Dapaah H, Lather J, Kaushik M, Bhullar JS. A review of Von Hippel-Lindau syndrome. J Kidney Cancer VHL. 2017;4(3):20-9.

31. Chittiboina P, Lonser RL. Von Hippel-Lindau disease. Handb Clin Neurol. 2015;132:139-56.

32. Agarwal R, Liebe S, Turski ML, Vidwans SJ, Janku F, Garrido-Laguna I, Munoz J, Schwab R, Rodon J, Kurzrock R, Subbiah V, pan-Cancer working group. Targeted therapy for genetic cancer syndromes: Von Hippel-Lindau disease, Cowden syndrome, and Proteus syndrome. Discov Med. 2015;19(103):109-16.

33. Pfander D, Kobayashi T, Knight MC, Zelzer E, Chan DA, Olsen BR, Giaccia AJ, Johnson RS, Haase VK, Schipani E. Deletion of Vhlh in chondrocytes reduces cell proliferation and increases matrix deposition during growth plate development. Development. 2004;131:2497-508.

34. Kirmani S, Young WF. Hereditary Paraganglioma-Pheochromocytoma Syndromes. In: Adam MP, Ardinger HH, Pagon RA, Wallace SE, Bean LH, Stephens K, Amemiya A, eds. SourceGeneReviews ${ }^{\oplus}$ [Internet]. Seattle (WA): University of Washington, Seattle; 2008[updated 2014 Nov 6]:1993-2018.
35. Welander J, Söderkvist P, Gimm O. Genetic and clinical characteristics of hereditary pheochromocytoma and paragangliomas. Endocr Relat Cancer. 2011;18:253-76

36. Liu Y, Liu L, Zhu F. Therapies targeting the signal pathways of pheochromocytoma and paraganglioma. Onco Targets Ther. 2019;12:7227-41.

37. Ayala-Ramirez M, Palmer JL, Hofmann MC, de la Cruz M, Moon BS, Waguespack SG, Habra MA and Jimenez C. Bone Metastases and Skeletal-Related Events in Patients with Malignant Pheochromocytoma and Sympathetic Paraganglioma. J Clin Endocrinol Metab. April 1, 2013; 98(4): 1492-1497.

38. Ahmed KS, Sherlock M, Stassen L, Timon C, Healy ML. Hyperparathyroidism jaw tumour syndrome (HPT-JT). Endocr Abstr. 2017;49:EP339.

39. Mehta A, Patel D, Rosenberg A, Boufraqech M, Ellis RJ, Nilubol N, Quezado MM, Marx SJ, Simonds WF, Kebebew E. Hyperparathyroidism-jaw tumor syndrome: results of surgical management. Surgery. 2014 Dec;156(6):1315-25.

40. Hyde SM, Rich TA, Waguespack SG, Perrier ND, Hu MI. CDC73-Related Disorders. In: Adam MP, Ardinger HH, Pagon RA, Wallace SE, Bean $\sqcup H_{\text {, }}$ Stephens K, Amemiya A, eds. SourceGeneReviews ${ }^{\oplus}$ [Internet]. Seattle (WA): University of Washington, Seattle; 2008 [updated 2018 Apr 26]:1993-2018.

41. Szabó J, Heath B, Hill VM, Jackson CE, Zarbo RJ, Mallette LE, Chew SL, Besser GM, Thakker RV, Huff V. Hereditary hyperparathyroidism-jaw tumor syndrome: the endocrine tumor gene HRPT2 maps to chromosome 1q21q31. Am J Hum Genet. 1995;56(4):944-50.

42. Cavaco BM, Barros L, Pannett AA, Ruas L, Carvalheiro M, Ruas MM, Krausz T, Santos MA, Sobrinho LG, Leite V, Thakker RV. The hyperparathyroidism-jaw tumour syndrome in Portuguese kindred. QJM. 2001;94(4):213-22.

43. Aboujaoude $\mathrm{S}$, Aoun $\mathrm{G}$. Juvenile trabecular ossifying fibroma of the maxilla: a case report. Med Arch. 2016;70(6):470-2

44. Oliveira FM, Makimoto TE, Scalissi NM, Marone MMS, Maeda SS. Regression of orbital brown tumor after surgical removal of parathyroid adenoma. Arch. Endocrinol. Metab. vol.59 no.5 São Paulo Oct. 2015 Epub Aug 28, 2015.

45. Droscha CJ, Diegel CR, Ethen NJ, Burgers TA, McDonald MJ, Maupin KA, Naidu AS, Wang P, Teh BT, Williams BO. Osteoblast-specific deletion of Hrpt2/Cdc73 results in high bone mass and increased bone turnover. Bone. 2017;98:68-78.

46. Farooq A, Walker $\amalg$, Bowling J, Audisio RA. Cowden syndrome. Cancer Treat Rev. 2010;36(8):577-83.

47. Nelen MR, Padberg GW, Peters EAJ, Lin AY, van den Helm B, Frants RR, et al. Localization of the gene for Cowden disease to 10q22-23. Nat Genet. 1996; 13:114-6.

48. Li DM, Sun H. TEP1, encoded by a candidate tumor suppressor locus is a novel protein tyrosine phosphatase regulated by transforming growth factor beta. Cancer Res. 1997;57(11):2124-9.

49. Pilarski R, Eng C. Will the real Cowden syndrome please stand up (again)? Expanding mutational and clinical spectra of the PTEN hamartoma tumour syndrome. J Med Genet. 2004;41(5):323-6.

50. Waite KA, Eng C. Protein PTEN: form and function. Am J Human Genet. 2002:70(4):829-44.

51. Liaw D, Marsh DJ, Li J, Dahia PLM, Wang SI, Zheng Z. Germline mutations of the PTEN gene in Cowden disease, an inherited breast and thyroid cancer syndrome. Nat Genet. 1997;16:64-7.

52. Ngeow J, Mester J, Rybicki LA, Ni Y, Milas M, Eng C. Incidence and clinical characteristics of thyroid cancer in prospective series of individuals with Cowden and Cowden-like syndrome characterized by germline PTEN, SDH, or KLLN alterations. J Clin Endocrinol Metab. 2011;96(12):E2063-71.

53. Komiya T, Blumenthal GM, DeChowdhury R, Fioravanti S, Ballas MS, Morris J, Hornyak TJ, Wank S, Hewitt SM, Morrow B, Memmott RM, Rajan A, Dennis PA. A pilot study of Sirolimus in subjects with Cowden syndrome or other syndromes characterized by Germline mutations in PTEN. Oncologist. 2019; 24(12):1510-e1265.

54. Yen BC, Kahn H, Schiller AL, Klein MJ, Phelps RG, Lebwohl MG. Multiple hamartoma syndrome with osteosarcoma. Arch Pathol Lab Med. 1993; 117(12):1252-4

55. Lopez C, Abuel-Haija M, Pena L, Coppola D. Novel Germline PTEN mutation associated with Cowden syndrome and osteosarcoma. Cancer Genomics Proteomics. 2018;15(2):115-20.

56. Liu X, Bruxvoort KJ, Zylstra CR, Liu J, Cichowski R, Faugere MC. Bouxsein ml, wan C, Williams BO and Clemens TL. Lifelong accumulation of bone in mice lacking Pten in osteoblasts. Proc Natl Acad Sci U S A. 2007;104(7):2259-64.

57. Hays E, Schmidt J, Chandar N. Beta-catenin is not activated by downregulation of PTEN in osteoblasts. Vitro Cell Dev Biol Animal. 2009;45: 361-70. 
58. Yang G, Sun Q, Teng Y, Li F, Weng T, Yang X. PTEN deficiency causes dyschondroplasia in mice by enhanced hypoxia-inducible factor 1a signaling and endoplasmic reticulum stress. Development. 2008;135:3587-97.

59. Carney JA. Carney Triad: A Syndrome Featuring Paraganglionic, Adrenocortical, and Possibly Other Endocrine Tumors. The Journal of Clinical Endocrinology \& Metabolism, Volume 94, Issue 10, 1 October 2009, Pages 3656-3662.

60. Kirschner LS, Sandrini F, Monbo J, Lin JP, Carney JA, Stratakis CA. Genetic heterogeneity and spectrum of mutations of the PRKAR1A gene in patients with the carney complex. Hum Mol Genet. 2000;9(20):3037-46.

61. Rothenbuhler A, Stratakis CA. Clinical and molecular genetics of Carney complex. Best Pract Res Clin Endocrinol Metab. 2010;24(3):389-99.

62. Robinson-White AJ, Bossis I, Hsiao HP, Nesterova M, Leitner WW, Stratakis CA. 8-Cl-adenosine inhibits proliferation and causes apoptosis in Blymphocytes via protein kinase A-dependent and independent effects: implications for treatment of Carney complex-associated tumors. J Clin Endocrinol Metab. 2009:94(10):4061-9.

63. Pavel E, Nadella K, Towns WH 2nd, Kirschner LS. Mutation of Prkar1a causes osteoblast neoplasia driven by dysregulation of protein kinase a. Mol Endocrinol. 2008;22(2):430-40.

64. Courcoutsakis NA, Tatsi C, Patronas NJ, Lee CC, Prassopoulos PK, Stratakis CA. The complex of myxomas, spotty skin pigmentation and endocrine overactivity (Carney complex): imaging findings with clinical and pathological correlation. Insights Imaging. 2013;4(1):119-33.

65. Carney JA, Boccon-Gibod L, Jarka DE, et al. Osteochondromyxoma of bone: a congenital tumor associated with lentigines and other unusual disorders. Am J Surg Pathol. 2001;25(2):164-76.

66. Zhang M, Manchanda PK, Wu D, Wang Q, Kirschner LS. Knockdown of PRKAR1A, the gene responsible for Carney complex, interferes with differentiation in Osteoblastic cells. Mol Endocrinol. 2014;28(3):295-307.

67. Saloustros E, Liu S, Mertz EL, Bhattacharyya N, Starost MF, Salpea P, Nesterova M, Collins M, Leikin S, Stratakis CA. Celecoxib treatment of fibrous dysplasia (FD) in a human FD cell line and FD-like lesions in mice with protein kinase a (PKA) defects. Mol Cell Endocrinol. 2017:439:165-74.

68. Crino PB, Nathanson KL, Henske EP. The tuberous sclerosis complex. N Engl J Med. 2006:355(13):1345-56

69. Curatolo P, Bombardieri R, Jozwiak S. Tuberous sclerosis. Lancet. 2008; 372(9639):657-68

70. Dworakowska D, Grossman AB. Are neuroendocrine Tumours a feature of tuberous sclerosis? A Systematic Review Endocr Relat Cancer. 2009; 16(1):45-58

71. Napolioni V, Curatolo P. Genetics and molecular biology of tuberous sclerosis complex. Curr Genomics. 2008;9(7):475-87.

72. Caban C, Khan N, Hasbani DM, Crino PB. Genetics of tuberous sclerosis complex: implications for clinical practice. Appl Clin Genet. 2017;10:1-8.

73. Curatolo P, Moavero R. mTOR inhibitors in tuberous sclerosis complex. Curr Neuropharmacol. 2012;10(4):404-15.

74. Prabhakar S, Zhang X, Goto J, Han S, Lai C, Bronson R, Sena-Esteves M, Ramesh V, Stemmer-Rachamimov A, Kwiatkowski DJ, Breakefield $X O$. Survival benefit and phenotypic improvement by hamartin gene therapy in a tuberous sclerosis mouse brain model. Neurobiol Dis. 2015:82:22-31.

75. Boronat S, Barber I, Thiele EA. Sclerotic bone lesions in tuberous sclerosis complex: a genotype-phenotype study. Am J Med Genet. 2017;173:1891-5.

76. Fang F, Sun S, Wang L, Guan JL, Giovannini M, Zhu Y, Liu F. Neural crestspecific TSC1 deletion in mice leads to sclerotic craniofacial bone lesion. J Bone Miner Res. 2015;30(7):1195-205.

77. Shen MH, Harper PS, Upadhyaya M. Molecular genetics of neurofibromatosis type 1 (NF1). J Med Genet. 1996;33(1):2-17.

78. Williams VC, Lucas J, Babcock MA, Gutmann DH, Korf B, Maria BL. Neurofibromatosis type 1 revisited. Pediatrics. 2009;123(1):124-33.

79. Lodish MB, Stratakis CA. Endocrine tumours in neurofibromatosis type 1 , tuberous sclerosis and related syndromes. Best Pract Res Clin Endocrinol Metab. 2010;24(3):439-49.

80. Walker JA, Upadhyayab M. Emerging therapeutic targets for neurofibromatosis type 1 (NF1). Expert Opin Ther Targets. 2018;22(5): 419-37.

81. Bai RY, Esposito D, Tam AJ, McCormick F, Riggins GJ, Clapp DW, Staedtke V. Feasibility of using NF1-GRD and AAV for gene replacement therapy in NF1associated tumors. Gene Ther. 2019;26:277-86.
82. Alwan S, Armstrong L, Joe H, Birch PH, Szudek J, Friedman JM. Associations of Osseus abnormalities in Neurofibromatosis 1. Am J Med Genet A. 2007 Jun 15;143A(12):1326-33.

83. Petramala L, Giustini S, Zinnamosca L, Marinelli C, Colangelo L, Cilenti G, Formicuccia MC, D'Erasmo E, Calvieri S, Letizia C. Bone mineral metabolism in patients with neurofibromatosis type 1 (von Recklinghausen disease). Arch Dermatol Res. 2012;304:325-31.

84. Tahaei SE, Couasnay G, Ma Y, Paria N, Gu J, Lemoine BF, Wang X, Rios JJ, Elefteriou $F$. The reduced osteogenic potential of Nf1-deficient osteoprogenitors is EGFR-independent. Bone. 2018;106:103-11.

85. Kolanczyk M, Kossler N, Kühnisch J, Lavitas L, Stricker S, Wilkening U, Manjubala I, Fratzl P, Spörle R, Herrmann BG, Parada LF, Kornak U, Mundlos S. Multiple roles for neurofibromin in skeletal development and growth. Hum Mol Genet. 2007;16(8):874-86

\section{Publisher's Note}

Springer Nature remains neutral with regard to jurisdictional claims in published maps and institutional affiliations.
Ready to submit your research? Choose BMC and benefit from:

- fast, convenient online submission

- thorough peer review by experienced researchers in your field

- rapid publication on acceptance

- support for research data, including large and complex data types

- gold Open Access which fosters wider collaboration and increased citations

- maximum visibility for your research: over $100 \mathrm{M}$ website views per year

At BMC, research is always in progress.

Learn more biomedcentral.com/submissions 